\title{
Application of the Soft X-Ray TSI Advanced Aerosol Neutralizer to Aerosol Measurements Made by a Grimm SMPS
}

\author{
Alessia Nicosia, Franco Belosi, Brais Vazquez \\ Institute of Atmospheric Sciences and Climate (ISAC), Italian National Research Council, Bologna, Italy \\ Email: a.nicosia@isac.cnr.it
}

Received 21 July 2014; revised 18 August 2014; accepted 6 September 2014

Copyright (C) 2014 by authors and Scientific Research Publishing Inc.

This work is licensed under the Creative Commons Attribution International License (CC BY). http://creativecommons.org/licenses/by/4.0/

c) (i) Open Access

\section{Abstract}

Scanning Mobility Particle Sizer (SMPS) spectrometers are subject to several restrictions when a radioactive source is employed to bring the aerosol to a steady-state charge distribution. An alternative solution, commercially available, is represented by the soft $\mathrm{X}$-ray neutralizer. The present study investigates the outcome of a combination of a Grimm SMPS, which employs a ${ }^{241} \mathrm{Am}$ radioactive source, with the soft X-ray advanced aerosol neutralizer (TSI model 3087). To date, the latter device has been interfaced only with TSI's Electrostatic Classifiers. Particle size distribution of sodium chloride aerosol was measured with both neutralizers and it was found that the particle number concentration agreed to be within $9 \%$ for the $10-700 \mathrm{~nm}$ range. This difference mainly corresponds to the bias reported by TSI, when the X-ray device is mounted on a TSI spectrometer. It was concluded that the $X$-ray neutralizer could be usefully employed, as a standalone device, in combination with Grimm Electrostatic Classifiers.

\section{Keywords}

Aerosol Neutralizer, SMPS, Particle Size Distribution

\section{Introduction}

Scanning Mobility Particle Sizers (SMPS) are widely used to classify submicron particulate matter according to their electrical mobility. They employ radioactive sources such as ${ }^{85} \mathrm{Kr}$, ${ }^{210} \mathrm{Po}$ or ${ }^{241} \mathrm{Am}$ to apply a well-known charge distribution to aerosols. However, these aerosol neutralizers are subject to several restrictions, especially in Europe, which limited their transport and handling.

Commercially available alternatives are the aerosol neutralizers based on a low energy $(<9.5 \mathrm{KeV})$ soft X-ray 
source. Such devices can be easily turned on and off, thereby increasing both safety and overall operating lifetime, and the respective regulations are more flexible.

Therefore, it is important to compare instruments working with radioactive and soft X-ray aerosol neutralizers. The novelty of this study was to evaluate the accuracy of the measurements obtained with a soft X-ray neutralizer (TSI, mod. 3087) in combination with a Grimm SMPS (L-DMA) under controlled laboratory conditions. TSI provides information on the neutralizer 3087 compared with the neutralizer $3077 \mathrm{~A}$ (based on ${ }^{85} \mathrm{Kr}$ ). However, all data and specifications apply to TSI instruments, since the X-ray neutralizer 3087 was specifically designed to interface with TSI's Electrostatic Classifier 3082.

Nevertheless, the aptness of this X-ray device assembled on a SMPS spectrometer other than TSI has not been reported in literature yet.

\section{Experimental Set-Up and Procedures}

The experimental set-up is schematically represented in Figure 1. Sodium Chloride particles were generated from a solution concentration of $1 \% \mathrm{w} / \mathrm{w}$, by means of a Collison nebulizer working at an operating pressure of 1 bar. The aerosol produced was slightly charged [1] and so, once dried inside a silica gel column, the particles were passed through a parallel plate condenser. The voltage applied to the condenser was previously adjusted in order to remove the charged portion of the aerosol, as verified by means of an aerosol electrometer. Experiments were carried out both with and without this voltage applied.

The resulting uncharged/charged polydisperse particles are hereinafter called "neutral/charged aerosol”, respectively. The aerosol was then diluted with purified air and carried into the 3087 TSI advanced aerosol neutralizer, followed by the Grimm SMPS spectrometer. Since the X-ray device was permanently fixed to the Grimm SMPS, the particles losses by Brownian diffusion inside the X-ray tube were the same for all the experiments. The ${ }^{241} \mathrm{Am}$ neutralizer was removed every time the X-ray device was turned on. Conversely, when the ${ }^{241} \mathrm{Am}$ neutralizer was inserted the X-ray device was switched off. This procedure was feasible as the aerosol particle number concentration was constant $( \pm 4 \%$ throughout 30 minutes of measurement controlled by a condensation particle counter, TSI mod. 3775). The Grimm SMPS spectrometer used in this study (SMPS + C Grimm Aerosol Technik GmbH \& Co. KG, Ainring, Germany) consists of a long differential mobility analyser (L-DMA model 5400 Vienna type) and a condensation particle counter (model 5.403). The standard neutralizer is a ${ }^{241} \mathrm{Am}$ source with an activity of $3.7 \mathrm{MBq}$. The particle size distribution was measured by neutralizing the aerosol alternatively with the ${ }^{241} \mathrm{Am}$ source or the X-ray neutralizer.

The data acquisition software (Grimm Universal Nano Software Version 1.2.3) was used for all measurements, based on the hypothesis that the charging ratio was the same for both neutralizers. This assumption was validated by Shimada et al. [2], who observed that the particle charging probabilities were equal whether using a

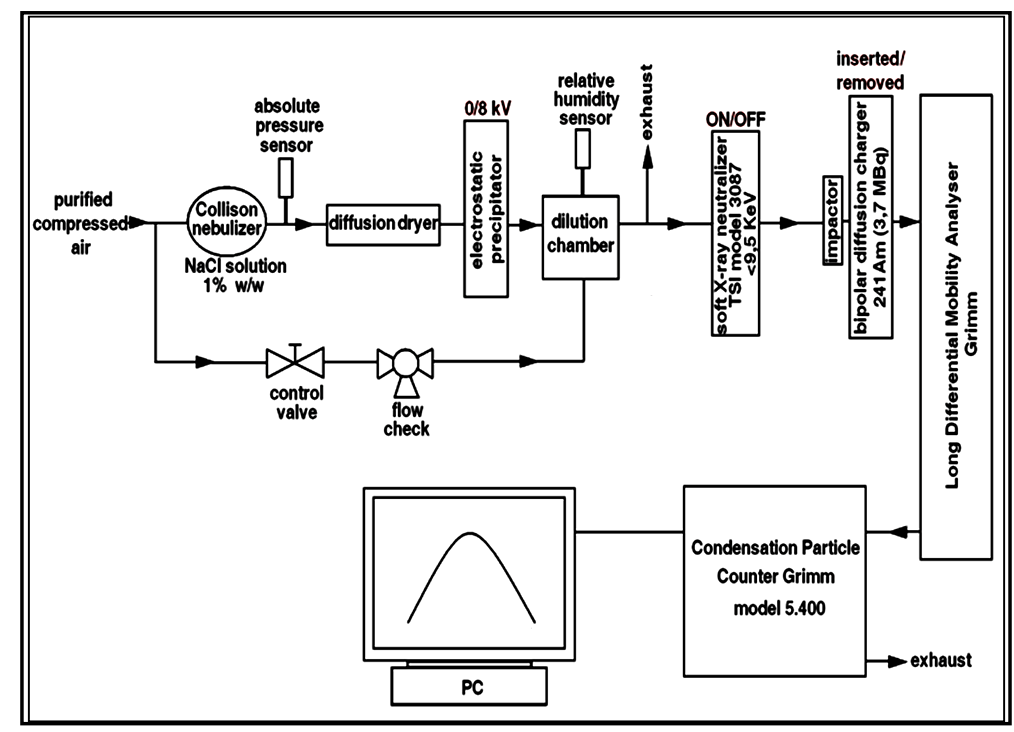

Figure 1. Experimental set-up. 
soft X-ray of $<9.5 \mathrm{keV}$ or a ${ }^{241} \mathrm{Am}$ foil source of $3.7 \mathrm{MBq}$ at two different particle residence times in the chargers $(0.5 \mathrm{~s}$ and $3 \mathrm{~s})$.

\section{Results and Discussion}

The average particle size distributions obtained with the two neutralizers are compared in Figure 2.

It was found that there is a slight decrease in the measured particle number concentration obtained with X-ray when compared to ${ }^{241} \mathrm{Am}$. For neutral sodium chloride particles, the difference of the total concentration was about 9\%, while for sodium chloride charged particles, it was about 3\% (see Table 1).

Figure 3 reports the paired absolute difference percentage (PADP), according to Watson et al. [3], defined as

$$
P A D P=100 * a b s\left(y_{i}-x_{i}\right) / x_{i}
$$

where $x_{i}$ and $y_{i}$ refer to the particle concentration of the $i$-th bin for the Grimm SMPS with ${ }^{241}$ Am neutralizer and with X-ray neutralizer, respectively. In the $10-700 \mathrm{~nm}$ size interval the average paired absolute difference is

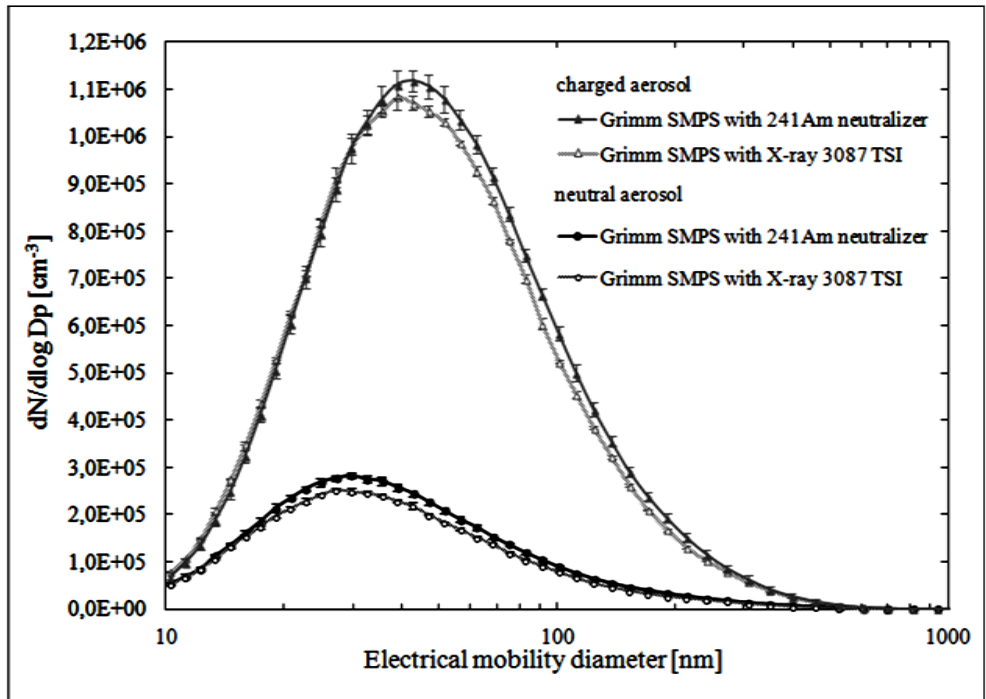

Figure 2. Aerosol size distribution for ${ }^{241} \mathrm{Am}$ and X-ray neutralizers (charged and neutral particles).

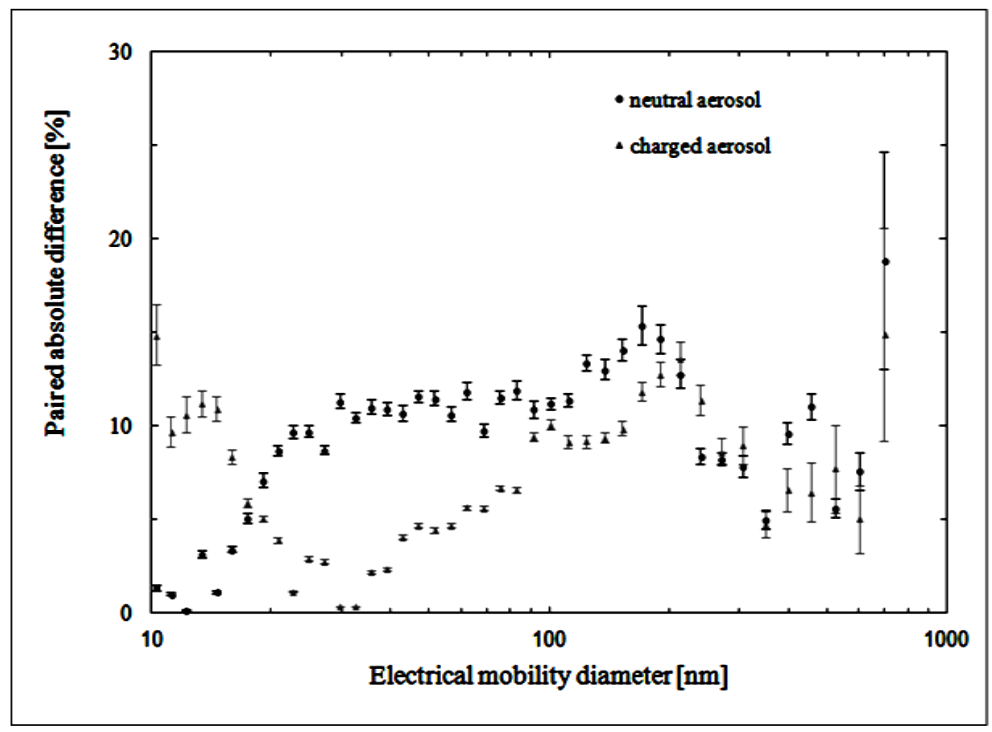

Figure 3. Paired absolute difference percentage. 
Table 1. Statistical parameters of the particle size distributions.

\begin{tabular}{cccc}
\hline & Median & Geom. St. Dev. & Total Conc. \\
\hline NEUTRAL AEROSOL & & & $(2.10 \pm 0.06) \cdot 10^{5} \mathrm{~cm}^{-3}$ \\
${ }^{241}$ Am neutralizer & $35.3 \pm 0.2 \mathrm{~nm}$ & $2.09 \pm 0.01$ & $(1.90 \pm 0.02) \cdot 10^{5} \mathrm{~cm}^{-3}$ \\
X-ray TSI 3087 & $34.6 \pm 0.2 \mathrm{~nm}$ & $2.09 \pm 0.01$ & $(9.4 \pm 0.3) \%$ \\
Relative difference (respect to $\left.{ }^{241} \mathrm{Am}\right)$ & $(1.88 \pm 0.01) \%$ & $(0.400 \pm 0.002) \%$ & $(8.5 \pm 0.2) \cdot 10^{5} \mathrm{~cm}^{-3}$ \\
CHARGED AEROSOL & & & $(8.2 \pm 0.2) \cdot 10^{5} \mathrm{~cm}^{-3}$ \\
${ }^{241}$ Am neutralizer & $47.0 \pm 0.5 \mathrm{~nm}$ & $2.01 \pm 0.01$ & $(3.2 \pm 0.1) \%$ \\
X-ray TSI 3087 & $45.2 \pm 0.2 \mathrm{~nm}$ & $(0.166 \pm 0.002) \%$ & $(2.04 \pm 0.18) \cdot 10^{3} \mathrm{~cm}^{-3}$ \\
INDOOR & $(3.80 \pm 0.04) \%$ & & $(1.84 \pm 0.12) \cdot 10^{3} \mathrm{~cm}^{-3}$ \\
Relative difference (respect to $\left.{ }^{241} \mathrm{Am}\right)$ & & $2.35 \pm 0.06$ & $(9.8 \pm 1.1)^{\circ} \%$ \\
\hline
\end{tabular}

about $9 \%$ for neutral aerosol and about 7\% for charged aerosol. The 700 - 1090 nm size range was not considered due to the low particle number concentration.

The mean statistical parameters were compared and are reported in Table 1. For both test aerosols, it was found that the peak of the distribution is slightly shifted backward for X-ray, and all statistical parameters are within $4 \%$.

These results should be compared with the values provided by TSI in the X-ray neutralizer datasheet. Highly charged particles of different type, size and concentration were investigated, after passing through a unipolar charger upstream of the SMPS spectrometer. TSI reports that the geometric means and geometric standard deviations for the entire test matrix were within 5\%, and the concentrations within $10 \%-20 \%$. TSI excluded that these differences were due to an incomplete charge neutralization of the X-ray device. The accuracy limit provided in the datasheet is greater than the differences observed in the present study. To extend our comparison, we used the Grimm SMPS to measure the distribution of indoor air at $25 \%$ relative humidity, with both the $\mathrm{X}$-ray and the ${ }^{241} \mathrm{Am}$ neutralizer. Four series were taken through each device and the average particle size distributions are illustrated in Figure 4.

Apart the 90 - $120 \mathrm{~nm}$ interval, the two particle size distributions are fully included inside the measurement variability. The statistical parameters, as well as the median and standard deviation show good agreement, while the total particle number concentration is $10 \%$ lower with X-ray than with ${ }^{241} \mathrm{Am}$.

Figure 5 shows the correlation of the average particle number concentration in each size bin (for indoor, uncharged and charged aerosol measurements) between the SMPS with ${ }^{241} \mathrm{Am}$ or X-ray neutralizers.

The correlation coefficient turned out to be 0.998, while the one reported in the TSI datasheet was 0.994, and compares well with the measurements reported in the literature for instruments of different design. Watson et al., [3] reported an average correlation of 0.95 in the 5 - $200 \mathrm{~nm}$ size intervals while comparing four different SMPS spectrometers (TSI nano, TSI standard, Grimm SMPS + C and MSP WPS) at Fresno Supersite.

In addition, Wiedensohler et al. [4] reported a discrepancy of 10\% in the 20 - $200 \mathrm{~nm}$ particle size range, and $30 \%$ for particles larger than $200 \mathrm{~nm}$, under controlled laboratory conditions, by comparing distributions measured with spectrometers of different design.

\section{Conclusions}

The applicability of the X-ray neutralizer (TSI model 3087) in combination with a Grimm SMPS (L-DMA) has been evaluated under controlled laboratory conditions. The comparison between the aerosol size distributions obtained with the standard Grimm neutralizer $\left({ }^{241} \mathrm{Am}\right.$ radioactive source) and with the soft X-ray neutralizer shows: 


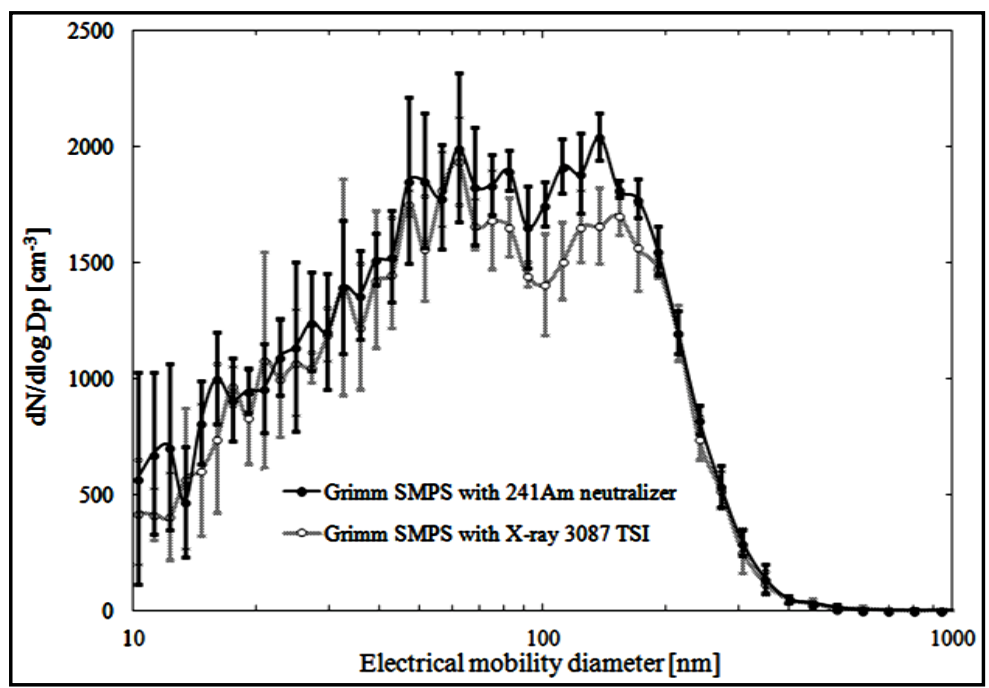

Figure 4. Indoor aerosol size distribution for 241Am and X-ray neutralizers.

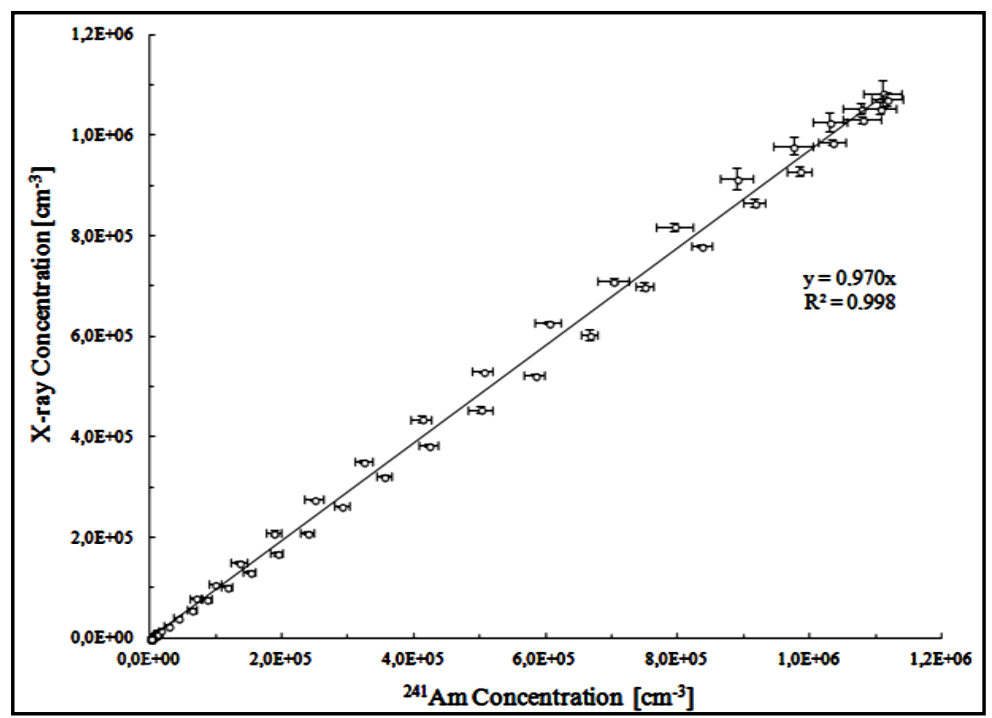

Figure 5. Particle concentration correlation between SMPS spectrometer data taken with the X-ray model 3087 TSI and the ${ }^{241}$ Am neutralizers.

- a 0.998 correlation in the particle number concentration;

- differences in the distribution parameters (median and geometric standard deviation) below 4\%;

- in the 10 - $700 \mathrm{~nm}$ size range the PADP is about 9\% for neutral aerosol and 7\% for charged aerosol. In conclusion our results show the applicability of the soft X-ray neutralizer as a standalone device.

\section{Acknowledgements}

This work was partially supported by the European Project "Smart Nano-structured Devices Hierarchically Assembled by Mineralization Processes” (SMILEY, NMP.2012.1.4-2 FP7 SMALL-6-310637).

We are particularly grateful to Dr. Gianni Santachiara for his constructive comments and corrections.

\section{References}

[1] Hoppel, W.A. and Frick, G.M. (1990) The Nonequilibrium Character of the Aerosol Charge. Distributions Produced by Neutralizers. Aerosol Science and Technology, 12, 471-496. http://dx.doi.org/10.1080/02786829008959363 
[2] Shimada, M., Han, B., Okuyama, K. and Otani, Y. (2002) Bipolar Charging of Aerosol Nanoparticles by a Soft X-Ray Photoionizer. Journal of Chemical Engineering of Japan, 35, 786-793. http://dx.doi.org/10.1252/jcej.35.786

[3] Watson, J.G., Chow, J.C., Sodeman, D.A., Lowenthal, D.H., Chang, O.M.C., Park, K. and Wang, X. (2011) Comparison of four Scanning Mobility Particle Sizers at the Fresno Supersite. Particuology, 9, 204-209. http://dx.doi.org/10.1016/j.partic.2011.03.002

[4] Wiedensohler, A., Birmili, W., Nowak, A., Sonntag, A., Weinhold, K., Merkel, M., Wehner, B., Tuch, T., Pfeifer, S., Fiebig, M., Fjäraa, A.M., Asmi, E., Sellegri, K., Depuy, R., Venzac, H., Villani, P., Laj, P., Aalto, P., Ogren, J.A., Swietlicki, E., Williams, P., Roldin, P., Quincey, P., Hüglin, C., Fierz-Schmidhauser, R., Gysel, M., Weingartner, E., Riccobono, F., Santos, S., Grüning, C., Faloon, K., Beddows, D., Harrison, R., Monahan, C., Jennings, S.G., O’Dowd, C.D., Marinoni, A., Horn, H.G., Keck, L., Jiang, J., Scheckman, J., McMurry, P.H., Deng, Z., Zhao, C.S., Moerman, M., Henzing, B., de Leeuw, G., Löschau, G. and Bastian, S. (2012) Mobility Particle Size Spectrometers: Harmonization of Technical Standards and Data Structure to Facilitate High Quality Long-Term Observations of Atmospheric Particle Number Size Distributions. Atmospheric Measurement Techniques, 5, 657-685.

http://dx.doi.org/10.5194/amt-5-657-2012 
Scientific Research Publishing (SCIRP) is one of the largest Open Access journal publishers. It is currently publishing more than 200 open access, online, peer-reviewed journals covering a wide range of academic disciplines. SCIRP serves the worldwide academic communities and contributes to the progress and application of science with its publication.

Other selected journals from SCIRP are listed as below. Submit your manuscript to us via either submit@scirp.org or Online Submission Portal.
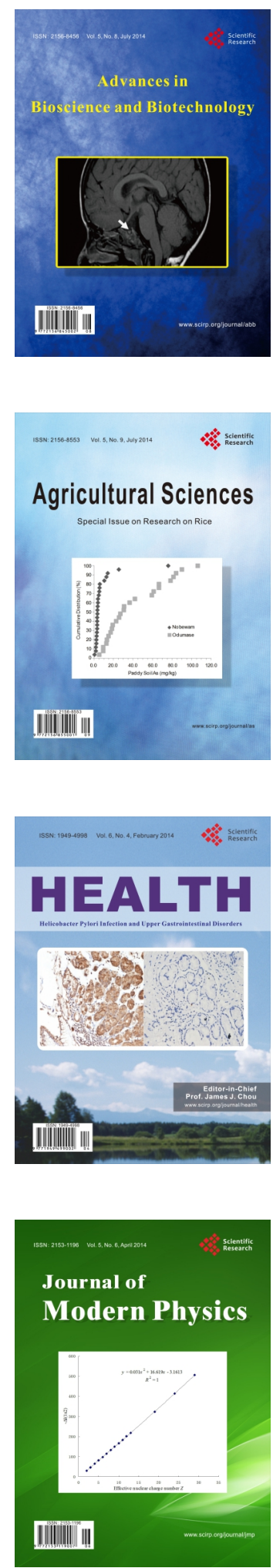
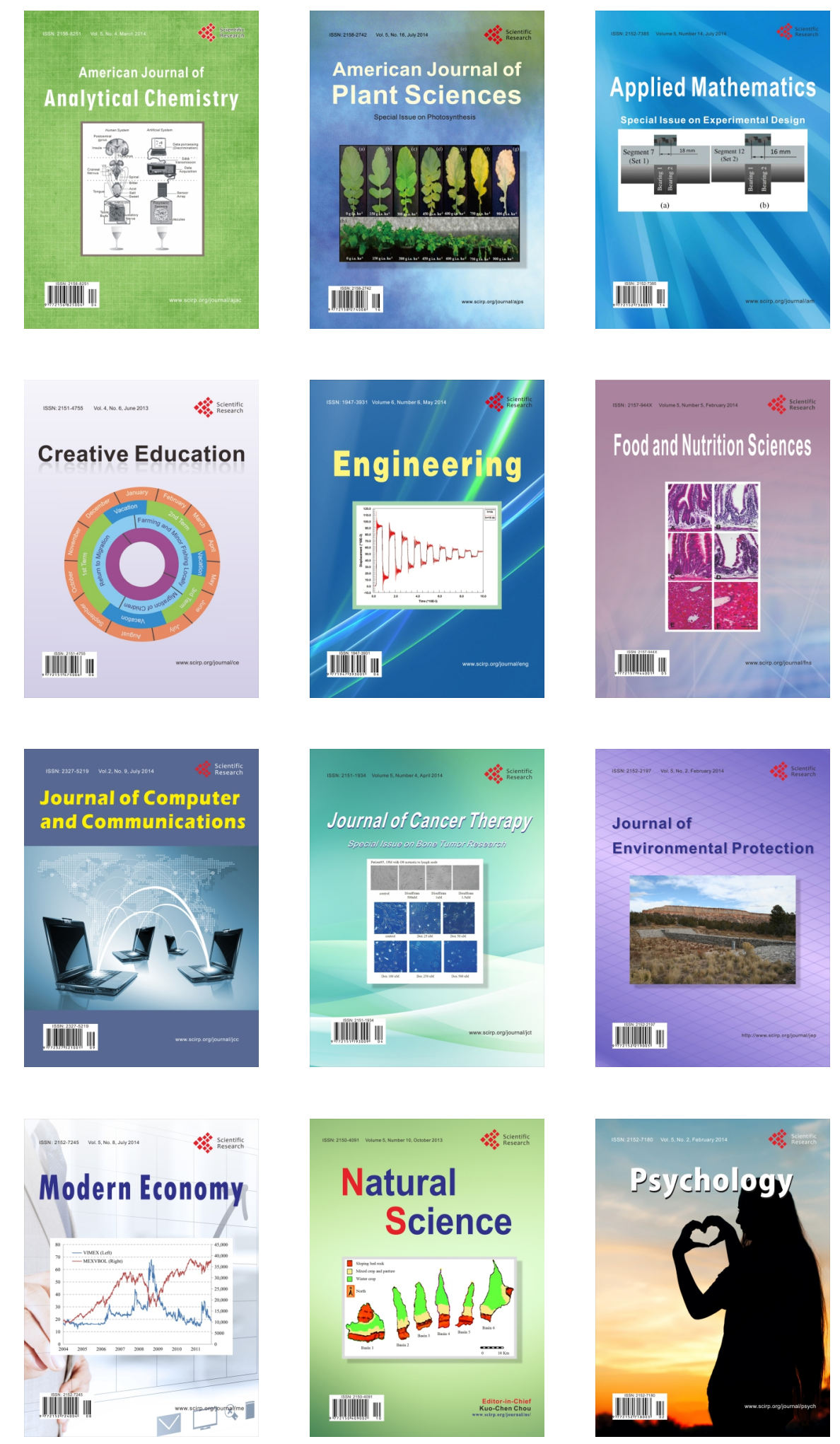